\title{
Bandung Metropolitan Transportation Planning Collaboration and Perceived Transaction Cost Changes after 2 Decades of Decentralization
}

\author{
Miming Miharja ${ }^{1^{*}}$, Johan Woltjer², Sheryta Arsallia' ${ }^{1}$, Azman Hafid Diab ${ }^{1}$ \\ ${ }^{1}$ School of Architecture, Planning, and Policy Development, Institut Teknologi Bandung, Jl. Ganesha 10 \\ Bandung 40132, Indonesia \\ ${ }^{2}$ Faculty of Spatial Sciences, University of Groningen, Landleven 1, 9747 AD Groningen, The Netherlands
}

\begin{abstract}
Roughly 2 decades ago, the Indonesian Decentralization Act 22/1999 (revised by Act $32 / 2004$ and Act 23/2014) initiated a remarkable shift in the governance system for Indonesia: from a strongly hierarchical system to a further decentralized one. The shift has created fragmented governance for metropolitan transportation planning. Consequently, Indonesian metropolitan areas have experienced increasing transaction costs in policy coordination and difficulties in supplying sufficient transport infrastructures. Earlier research has pointed to a range of possible solutions, including strengthening local government capacity. This paper sets out to identify current perceptions regarding transaction costs in Indonesian metropolitan transportation planning. To what extent do high transaction costs create fragmented planning? Have planning actors' perceptions changed over time? Using Q-methodology and in-depth interviews, the research identifies significant changes in actors' perceptions, mainly towards the need to establish supraregional institutions and regional development priorities. The findings are critical for institutional reformulation to support comprehensive transportation planning at the metropolitan level.
\end{abstract}

Keywords: Decentralization; Metropolitan transportation planning; Transaction costs

\section{Introduction}

A decentralized governance system has been implemented in Indonesia since 1999 (following the Decentralization Act 22/1999, revised by Act 32/2004 and Act 23/2014). These legislative changes have affected the Indonesian governance system, which was initially highly hierarchical, to become much less hierarchical (Seymour and Turner, 2002). Under Decentralization Act, the central government, to a great extent, has lost much of its power, while local governments wield greater authority in managing their area. A typical consequence of decentralization is that, while it encourages local government's autonomous decision-making, it also tends to motivate them to solely focus on their respective territories (Firman, 2009). The consequence of this situation to planning fragmentation is quite predictable; local governments might easily neglect crossjurisdictional development issues and tend to focus on their inward-looking programs in response to their inhabitants demands (Lowery, 2000).

A metropolitan area refers to an extensive region where urban functions and activities across the area are interconnected. For transportation, in particular, metropolitan problmes such as congestion, pollution, and economic loss are directly related to the

${ }^{*}$ Corresponding author's email: mimingm@pusat.itb.ac.id, Tel.: +62-8112249370, Fax.: +62-22-2501263 doi: 10.14716/ijtech.v12i3.4345 
success or failure of efficient transport service provision, whose planning issues would go beyond the boundaries of one local government. Fragmented planning by local governments can easily result in an unbalance between transport demand and supply, which has been a fundamental cause of severe metropolitan transportation issues today (Hirschhorn et al., 2019).

From a transaction theory point of view, inter-local collaboration is assumed to be voluntary, while decision-making processes are dominated by cost and benefit considerations (Alexander, 1992; Feiock, 2005). The transaction-cost theory is often used to express social costs inherent to activities needed for coordination in policy-making processes. These activities include exploring possible projects, trust-building, agreement making, meetings, communication, setting up partnerships, and dispute resolution (Hijdra et al., 2014).

The application of transaction-cost theory has been used to study cooperation between firms (North, 1990), or, over the last two decennia, between public organizations as well (Alexander, 2001). A focus on transaction costs for applied fields such as transport management or urban and environmental planning is more recent (Hijdra et al., 2014; Boschet and Rambonilaza, 2018). An emerging debate is about the linkages between transaction costs and institutional design for planning policies. Different institutional characteristics, such as those distinctive to transportation planning, will imply different transaction costs.

This study has taken a transaction cost perspective to deepen our understanding of the interdependence of local governments for transport issues in metropolitan areas, where coordination requires a suitable institutional design by which roles, interests, and actions among them are well-coordinated. Taking Bandung Metropolitan (BM) as the case study, this study aims to understand the dynamics of the transaction cost elements under the decentralized governance system over the past 2 decades. While contributing to the literature in this field of interest, the findings would also be the bases for an institutional redesign for better interlocal government transportation planning collaboration in BM.

\section{Methods}

\subsection{Literature Review}

There is a substantial body of research on issues of institutional design concerning urban and regional development and planning. Naruetharadhol et al. (2020), for example, discuss how the recognition of green innovation affects organizational structures and helps stakeholders commit to, and engage with, an organization's environmental objective. Another recent study (Zhogova et al., 2020) explores a methodology based on a cluster approach for identifying priority development areas for small and medium-sized enterprises in the Leningrad Region, Russia. Other recent studies performed quantitative assessments of the perceived role of interregional interaction to facilitate regional economic growth (e.g., Kozonogova et al., 2020).

Among others, the transaction cost approach has been widely employed to establish implications and suggestions for any institutional design. Less hierarchical governance structures, for example, might easily imply an uncoordinated and disintegrated metropolitan transportation planning process associated with considerable transaction cost. One example includes the identification of transaction cost elements as the basis for institutional design to improve multimodal service performance in Tanjung Priok Port, Indonesia (Budisiswanto et al., 2020). Another example involves an examination of costs inherent to vertical integration and vertical separation from a transaction cost perspective in public rail transport systems (Mizutani et al., 2015). Wegelin and Von Arx (2016) have 
analyzed transaction costs embedded in different governance forms, particularly looking at competitive tendering in Germany and direct awarding in Switzerland and how they imply decisions around competition in public rail transport. Finally, Canonico et al. (2013) have shown a clear alignment between transaction dimensions and governance structures in Italian public transport systems using a transaction cost perspective.

A previous study on the Bandung Metropolitan case by Miharja and Woltjer (2010) identified four planning actors' perception systems on how high transaction costs led to fragmented processes in Bandung Metropolitan transportation planning. These perceptions highlighted legalistic and cultural aspects relevant to the local government and the importance of strengthening local government power in land-use planning. The perceptions were a typical product of the specific socio-cultural-economic-political circumstances influenced by the sudden change from a centralized government in Indonesia to a more decentralized system. Over 2 decades of decentralization, some questions are interestingly rising: what transaction costs dominate Indonesian metropolitan transportation planning now? Do high transaction costs still exist, and do they create a fragmented planning process? Are planning actors' perceptions still the same, or have they changed compared to those found nearly a decade ago? If they do change, what sort of factors stimulates this change? Answers to these questions are useful to learn from previous periods' successes and failures to understand the key factors for future Indonesian metropolitan transportation planning collaboration success.

This paper examines present-day Indonesian metropolitan transportation planning from a transaction cost theory point of view, focusing on answering the above set of questions. Based on the BM case, this research aims to identify changing actors' perceived transaction cost elements that may hamper coordination for metropolitan transportation planning during the last 2 decades. A crucial matter for assessing transaction cost has been in the perceptions of actors involved in planning coordination. Authors such as Buckley and Chapman (1997) asserted that these perceptions were not expressed in numbers but language. Generally, it is the perception of transaction cost issues that determines the outcome of coordination activities, and that perception tends to receive linguistic, not numerical, expression. Therefore, the analytical framework of this study refers to a synthesis of comparison between planning actors' perceived transaction cost elements over the 2 decades of decentralization. While identifying the simplified structure of present-day actors' perception systems, this framework also covers the exploration of socio-culturaleconomic-political dynamic, which has stimulated their perceptions. Such identification and exploration offer a unique scholarship contribution to the literature of the transaction cost theory and institutional design debate through the findings of present-day actors' perceived transaction costs elements and explanations concerning how they have changed over 2 decades in a decentralized governance context. This study is crucial to understand the implications of actors' perception changes to the specific need for an institutional redesign of BM transportation planning collaboration.

\subsection{Methods}

While focused on identifying the different transaction cost elements with the previous study, the nature of both research questions is similar. Therefore, similar methodologies are applicable: Q-methodology, in-depth interviews, and qualitative descriptive methodology. First of all, based on preliminary interview results, this research seeks to find out to what extent the Indonesian metropolitan transportation planning realm still represents itself as the product of a decentralized governance system. Furthermore, Qmethodology identifies today's planning actors' main perception systems. These systems are considered elements that influence the value of the "perceived" transaction costs of 
today's inter-local government transportation planning collaboration. The qualitative descriptive method is applied to dig out the factors within actors' perceptions. Five planning-actor categories-executive, legislative, non-government organization, expert, and private sector-were involved in the survey. Fourteen respondents fairly distributed over each of the five actor categories were taken from each of the five local governments. They were selected based on the criterion that their field of work was related to transportation planning decision-making. The respondent sample includes four executives (West Jawa Province, Bandung City, Cimahi City, and Bandung Regency Planning Boards), three legislatives (Bandung City, Cimahi City, and Bandung Regency House of Local People Representatives), three academicians/experts (Urban and Regional Planning-Institute of Technology Bandung, Civil Engineering-Institute of Technology Bandung, and Social and Political Sciences-University of Padjadjaran), two Non-Government Organizations (Indonesian Transport Society and NGO "Inisiatif"), and two private sectors (Batununggal Regency and Bhumi Cipta Suwarna Developers). This paper follows suggestions by Weiss (1994) who argued that many qualitative interview studies do not use samples at all but panels: "people who are uniquely able to be informative because they are expert in an area or privileged witnesses to an event."

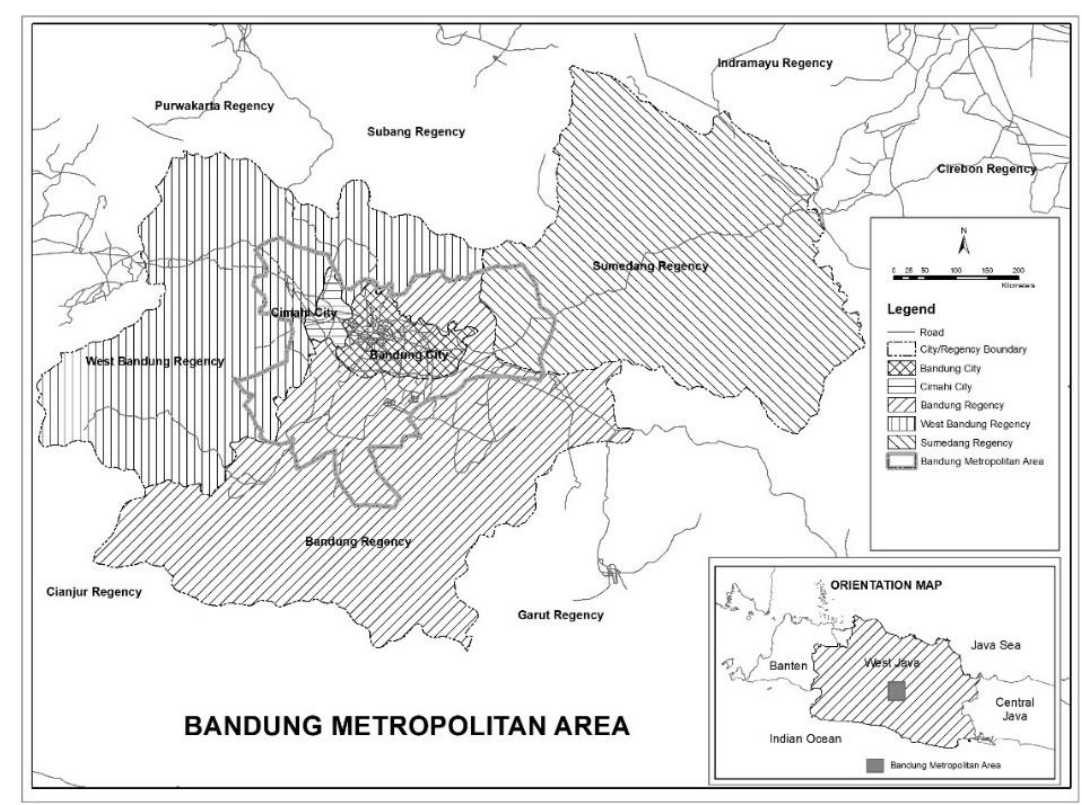

Figure 1 Bandung metropolitan area

Respondents involved in Q-sorting ranked and sorted a series of statements related to transportation coordination and in-depth interviews, which were conducted simultaneously. The process of Q-sorting and interviewing was closed at the point when saturation emerged, so additional viewpoints did not lead to new emergent themes and ranks (Strauss and Corbin, 1998). The determination of the saturation point is based on indepth interview results, which were found to be stagnant for the fourteenth respondent. This stagnant interview result is considered to be the saturation point for Q-sorting as well. The Bandung Metropolitan is chosen as the study case to allow a comparative analysis with the 2009 study. Figure 1 shows Bandung Metropolitan, consisting of five local governments (Cities: Bandung and Cimahi; Regencies: Bandung, West Bandung, and Sumedang).

Q-methodology is useful to reveal subjectivity (Brown, 1996). It can transform points of view into a structured perception system, which makes them easier to analyze. This 
method suits the purpose of revealing actor-perceived transaction costs. There are several stages in the Q-methodology process: identifying concourse; developing Q-sample (Q-set); selecting P-sets (respondents); performing Q-sorting; analysis and interpretation. Qmethodology is a semi qualitative-quantitative model because it involves the respondent's qualitative and quantitative scoring responses during the Q-sort process.

Meanwhile, in-depth interviews have helped to explore the basic explanatory factors that form actors' perception systems. The in-depth interview results provide a clearer explanation of why such a perception system became a major concern of the actors. First, taped interviews were transcribed into written text (Kent, 1998). The second stage involved coding and categorizing. This was done by grouping answers and concepts that pertain to the same phenomenon (Strauss and Corbin, 1998). The process began with immersion reading and rereading text; then, the identified themes were coded, subsequently displaying, in detail, information relevant to each category; afterward, this information was distilled to its essential points (Ulin et al., 2002). Finally, the data were interpreted, which involved considering their implications, making comparisons, and drawing conclusions.

\section{Results and Discussion}

\subsection{Q-Methodology Analysis Results: Identifying and Comparing Perception Systems}

Q-Methodology identifies five of today's planning actors' perception systems (PSs) that significantly influence their decision regarding transportation planning collaboration. The five PSs cover $77 \%$ of the total variation; thus, they can be considered a good representation. This section elaborates the five PSs; it additionally covers a comparative analysis with the 2009 research results. The next five tables show significant statements which form the collective meaning for each PS. Z-score of each statement (in brackets) indicates a statement's degree of contribution to the forming of the PS.

Table 1 PS-1: Pro supra-regional institution (38\%)

\begin{tabular}{|c|c|}
\hline Statements (z-score) & \\
\hline $\begin{array}{l}\text { - Local government initiative is not important } \\
\text { in forming collaboration in Bandung } \\
\text { Metropolitan transportation planning (- } \\
\text { 2.076). } \\
\text { - It is better to create a specific institution } \\
\text { responsible for metropolitan area } \\
\text { transportation planning (1.859). }\end{array}$ & $\begin{array}{l}\text { - Local government funds are better allocated for } \\
\text { other programs, such as public salary increases } \\
\text { or health, rather than transportation planning } \\
\text { collaboration (-1.463). } \\
\text { The unclear authority division and their role in } \\
\text { funding hamper collaboration among local } \\
\text { governments in metropolitan transportation } \\
\text { planning (1.458). }\end{array}$ \\
\hline
\end{tabular}

As shown in Table 1, "Pro supra-regional institution" appears to be the most important PS in today's actors' perceived transaction costs, covering 38\% of the overall variation of actors' perception. Meanwhile, nearly a decade ago, actors' weak willingness to support Bandung Metropolitan transportation planning collaboration was mainly stimulated by distrust in legal assurances due to inconsistent law enforcement. The "pro supra-regional institution" PS is underpinned by the first two statements. Actors are generally against the statement "Local government initiative is not important in forming collaboration in Bandung Metropolitan transportation planning (z score $=-2.076$ )", which means that local government initiatives are important but need to be well-coordinated by strong supraregional institutions. This PS is also supported by the second most important statement: "It is better to create a specific institution responsible for metropolitan area transportation planning $(\mathrm{z}$ score $=1.859)$ ". 
Table 2 shows that political and socio-economic aspect is taking the second position today. Previously, this PS was in the fourth position, which was the lowest rank PS. The shift means that this PS has become a more important consideration. This PS is formed by the actors' disagreement with the statement, "Leaders from each local area lack a strong commitment to metropolitan transportation planning collaboration, so they have less courage in taking innovation" (z-score $=-2.286$ ). This PS indicates that local governments' strong commitment is essential in forming collaboration. Moreover, this PS is also formed by the actors' agreement with the statement, "Local government funds are better allocated for programs, such as public salary increases or health, rather than transportation planning collaboration" (z-score $=1.538)$.

Table 2 PS-2: Political and socio-economic aspects (14\%)

\begin{tabular}{|c|c|}
\hline Statements (z-score) & \\
\hline $\begin{array}{l}\text { Leaders from each local area lack a strong } \\
\text { commitment to metropolitan transportation } \\
\text { planning collaboration, so they have less } \\
\text { courage in taking innovation } \\
(-2.286) \text {. } \\
\text { Local government funds are better allocated } \\
\text { for programs, such as public salary increases } \\
\text { or health, rather than transportation planning } \\
\text { collaboration (1.538). }\end{array}$ & $\begin{array}{l}\text { - It is better to create a specific institution } \\
\text { responsible for metropolitan area } \\
\text { transportation planning (1.524). } \\
\text { The benefits of transportation planning } \\
\text { collaboration are mostly enjoyed by the } \\
\text { Bandung Metropolitan center (1.150). } \\
\text { Commitment resulting from } \\
\text { transportation planning collaboration } \\
\text { restricts private sector flexibility, which } \\
\text { may hamper local economy development } \\
(-1.150) \text {. }\end{array}$ \\
\hline
\end{tabular}

Table 3 PS-3: Regional development priority (11\%)

\begin{tabular}{lll}
\hline \multicolumn{1}{c}{ Statements (z-score) } & \\
\hline - Local government funds are better allocated & $\bullet$ & $\begin{array}{l}\text { Social awareness in collaboration has risen } \\
\text { for other programs, such as public salary } \\
\text { increases or health, rather than transportation } \\
\text { planning collaboration (1.964). }\end{array}$ \\
$\begin{array}{l}\text { The benefit of transportation collaboration will } \\
\text { be gained in the long run, so it is not politically } \\
\text { interesting for local leaders (-1.964). }\end{array}$ & $\begin{array}{l}\text { due to fragmented transportation planning } \\
\text { (1.309). }\end{array}$ \\
& $\begin{array}{l}\text { Collaboration among local governments in } \\
\text { transportation planning is the responsibility } \\
\text { of the central government, not the local }\end{array}$ \\
& government (1.309). \\
\hline
\end{tabular}

Table 3 shows that regional development priority appears as the third important PS in today's actor-perceived transaction cost elements. This PS is strongly influenced by the statement, "Local government funds are better allocated for other programs, such as public salary increases or health, rather than transportation planning collaboration" (z score = 1.964). It indicates the urgency regarding regional development priorities to improve society's welfare. This PS is also supported by the statement: "The benefit of transportation collaboration will be gained in the long run, so it is not politically interesting for local leaders (z score $=-1.964$ ). This would mean that actors perceive that, in a political sense, even though a planning collaboration program may only be sensible long term, it is considered politically interesting to support regional development. 
Table 4 PS-4: Private sector collaboration (8\%)

\begin{tabular}{lll}
\hline \multicolumn{1}{c}{ Statements (z-score) } & \\
\hline - Leaders from each local area rarely have a & $\bullet$ & The benefit of transportation collaboration will \\
strong commitment to metropolitan & be gained in the long run, so it is not politically \\
transportation planning collaboration (1.904). & interesting for local leaders (1.309). \\
- Commitment resulting from transportation & The unclear authority division and their role in \\
planning collaboration restricts private sector & funding hamper the collaboration among local \\
$\begin{array}{l}\text { flexibility, which may hamper local economic } \\
\text { development (-1.785). }\end{array}$ & $\begin{array}{l}\text { governments in metropolitan transportation } \\
\text { planning (1.309). }\end{array}$ \\
\hline
\end{tabular}

Table 4 also displays a new appearing perception system concerning private sector collaboration. This PS is strongly influenced by the statement, "Leaders from each local area rarely have a strong commitment to metropolitan transportation planning collaboration ( $\mathrm{z}$ score $=1.904$ ), which means, despite the more convincing legal assurance indicated in the first PS, actors somehow still do not fully trust the other local governments. Simultaneously, they hope the governments allow the private sector more flexibility, as represented by the second statement: "Commitment resulting from transportation planning collaboration restricts private sector flexibility, which may hamper local economic development" (z score $=-1.785$ ). This would mean that a collective agreement derived from the transportation planning collaboration is believed to positively create a more unified regulation flexibility in Bandung Metropolitan to attract more private sectors doing business.

Table 5 PS-5: Local government culture (6\%)

\begin{tabular}{|c|c|}
\hline Statements (z-score) & \\
\hline $\begin{array}{l}\text { - Local government initiative is not } \\
\text { important in forming collaboration in } \\
\text { Bandung Metropolitan transportation } \\
\text { planning } \\
(-2.162) \text {. } \\
\text { Collaboration among local governments in } \\
\text { transportation planning is the } \\
\text { responsibility of the central government, } \\
\text { not the local government }(-1.644) \text {. }\end{array}$ & $\begin{array}{l}\text { - It is better to create a specific institution } \\
\text { responsible for metropolitan area } \\
\text { transportation planning (1.631). } \\
\text { - Social awareness in collaboration has risen } \\
\text { because the negative effects of the } \\
\text { transportation problem were experienced } \\
\text { due to fragmented transportation planning } \\
\text { (1.623). }\end{array}$ \\
\hline
\end{tabular}

Table 5 displays that local government culture appears to be the fifth important PS. This PS is supported by actors' disagreement with the statement "Local government initiative is not important in forming collaboration in Bandung Metropolitan transportation planning (z-score = -2.162)". Actors' disagreement with this statement indicates that local government initiative is considered important in Bandung Metropolitan transportation planning. The PS reflects a significant perception change that, in the current situation, has been the growing perception of actors' concerning the importance of local government initiatives in metropolitan transportation collaboration.

\subsection{In-depth Interview Results: Explaining Actors' Perception Systems Changes}

This section provides a descriptive analysis of actors' perception changes during the last 2 decades of decentralization, which are mainly based on in-depth interview results. Some parts of the analysis are also enriched through secondary data. It can be concluded that after 2 decades of decentralization, the current set of elements influencing perception systems in today's Bandung Metropolitan transportation planning are: (1) unclear authority in metropolitan area transportation planning leads to the growing need for transportation planning collaboration led by a supra-regional institution; (2) political and 
socio-economic aspects, mainly due to the stronger local leader's commitment and innovation as well as the stronger need for local economic development; (3) regional development priorities, local government budget shortages have caused transportation planning collaboration not to be a top priority compared to short-term citizen welfare improvement programs; (4) collaboration with the private sector is more desirable in the form of local government coordinated engagement; (5) Local government initiative on metropolitan transportation planning collaboration is perceived as becoming more important to produce a comprehensive metropolitan transportation plan. This is required to overcome the old governance cultures of patrimony, skepticism, and clientelism, which is seen as less suitable for collaborative planning.

Unlike what actors perceived 2 decades ago, today's actors' perception of the importance of legal assurance is no longer the most significant one. The disappearance of this legal aspect PS is likely due to the fact that several inter-governmental planning collaboration regulations had been enacted and consistently implemented during this period.

This research also identifies a meaningful change in the government culture PS, which has moved from the first to the fifth position. In-depth interviews reveal that some traditional government cultural values, which previously discouraged the spirit of planning collaboration (patrimony, skepticism, and clientelism), tend to be down-scaling. On the element of patrimony, the growing awareness among the local leaders on the need for collaboration has encouraged them to support planning collaboration. On clientelism, strict law enforcement carried out by the Komisi Pemberantasan Korupsi (KPK, Commission of Corruption Eradication) has reduced these practices. As for skepticism, it is reduced by a growing number of better-educated staffs who join the local government.

Supra-regional institution PS has moved from the third position to the first position. This is the most meaningful actor perception change. Actors observe that an incomprehensive metropolitan transportation plan, as a product of a fragmented planning process, has resulted in a much worse transport situation at the metropolitan scale. This has improved actors' awareness of the importance of supra-regional institutions that can act as a facilitator.

On the socio-economic and political aspects, it is found that the influence of this PS has decreased. In the case of the Bandung Metropolitan and beyond, higher education levels have increased public awareness of the importance of regional transportation planning collaboration. Better levels of education among citizens are indicated by the increased the Angka Partisipasi Pendidikan Tinggi/APPT (Higher Education Participation Index) the number of the youngsters who registered in universities compared to those at higher education age groups, to as many as 20.5\% (2011) and 29.4\% (2018; Statistics of West Jawa Province, 2018).

The first newly appearing PS is regarding regional development priorities. This can be explained by the fact that, in the larger part of Bandung Metropolitan, citizens' current welfare level has not yet reached the minimum regional wage standards (Jawa Barat Province in Figures, 2019). Among the five local governments, only Bandung City and Cimahi City have their average family income above the regional minimum wage standard.

Another newly appearing PS involves actors' concerns about strengthening coordinated cooperation with the private sector. The two strongest statements in this PS reflect a distrust of local leaders' commitment to comply with the collective agreement. However, actors would support planning collaboration whenever they are involved in the private sector investment agreement process, potentially giving equal benefit to all participants. 


\subsection{Discussion: Transaction Cost and Institutional Design}

This paper particularly discusses the fragmented Indonesian metropolitan transportation planning problem from the perspective of planning actors' perceived transaction costs. The findings represent a case of efforts to coordinate collective transport decisions in a decentralized metropolitan context. The study confirms that transport collective decisions at the metropolitan level are associated with significant and high transaction costs. The Bandung Metropolitan transportation planning case clearly shows that perceptions around suitable institutional design to address regional transport have changed over the last decade. The idea of establishing a stronger supra-regional authority to effectively coordinate planning collaboration, rather than strengthened local government agencies, has become more prominent.

Interestingly, this analysis suggests the appearance of a new actors' perception system: a perception system emphasizing regional development priorities as an element associated with their willingness to support transportation planning collaboration. Another new perception system is the importance of partnership with the private sector. This perception is based on experiences such as unequal benefits of private sector investments in urban development and related infrastructures or undesirable competitive situations between local government agencies.

A useful interpretation of the above findings from the perspective of institutional design refers to the theoretical idea that transaction costs could be minimalized by selecting a certain governance type (Williamson, 1981). Developing a transaction cost economics view of governance structures, Williamson regarded the transaction as the central unit of analysis and argued that the comprehension of transaction cost economizing was crucial for the study of organizations by assessing to what degree their governance structures helped economize these transaction costs (Canitez, 2019). In the Bandung Metropolitan case, the institutional framework that fits the effort to reduce transaction costs under the new circumstances should be based on the effort to return authority to an acceptable level in order to form a stronger supra-regional institution. In other words, to bring back a more hierarchical governance framework.

We also found that the transaction cost in this research case is significantly influenced by planning actors' perception of the importance of socio-economic welfare improvement through regional development, which requires private sector coordinated involvement. Therefore, the supra-regional institutional framework is expected to focus not only on promoting better interlocal government transportation planning collaboration but also on incorporating a clear context of every transportation plan with public welfare improvements and adding private sector involvement that allows relatively balanced benefits for all local governments.

However, re-establishing a stronger supra-regional institution should proceed carefully, as local governments might see it as a setback from a broader decentralization spirit. While putting back considerable planning authority to supra-regional institutions, an effort should be made to include aspects of 'relational contracting' as a part of the regionalized institutional setting (Williamson, 1985; Buitelaar, 2007). Institutional arrangements for relational contracting refer to a third form of governance structure following new institutional-economic reflections to Coase dichotomy, set up between market and hierarchy. This category is usually captured under the heading 'network' or 'policy networks' (Williamson, 1985; Hawkins et al., 2016). Here, networks imply institutional arrangements featuring economic development partners, informal groups, mutual-aid organizations, small-scale and local institutional networks, cooperative forms of social existence, and so on (Thompson, 2003). 


\section{Conclusions}

This research has identified a remarkable shift in perceived transaction cost over a decade for a case of transportation planning coordination in a profoundly decentralized context (involving the case of Bandung Metropolitan transportation planning collaboration). An earlier study in 2010 concluded that Indonesian decentralization had required a much stronger local government authority, which has subsequently stimulated various manifestations of fragmented metropolitan transportation planning. A lack of strong, consistent legal assurance and government cultural constraints were found to be the most influencing elements that created a high transaction cost at that time. However, dynamic socio-economic and political processes over a decade have changed the decisionmaking of planning actors who most influence perceived transaction cost elements to support or not support metropolitan transportation planning collaboration. This research reveals that today's most influencing transaction cost elements involve the reestablishment of supra-regional institutions and promoting regional development through private sector-coordinated participation. The research suggests that giving back authority at an acceptable level to supra-regional institutions would reduce the value of transaction costs. However, while practicing its greater authority to promote a stronger metropolitan transportation planning coordination, this supra-regional institution should focus on regional economic developments by involving the private sector in well-coordinated engagement.

\section{References}

Alexander, E.R., 1992. A Transaction Cost Theory of Planning. Journal of The American Planning Association, Volume 58(2), pp. 190-200

Alexander, E.R., 2001. A Transaction-Cost Theory of Land Use Planning and Development Control: Towards the Institutional Analysis of Public Planning. The Town Planning Review, Volume 72(1), pp. 45-75

Boschet, C., Rambonilaza, T., 2018. Collaborative Environmental Governance and Transaction Costs in Partnerships: Evidence from a Social Network Approach to Water Management in France. Journal of Environmental Planning and Management, Volume 61(1), pp. 105-123

Brown, S.R., 1996. Q Methodology and Qualitative Research. Qualitative Health Research, Volume (4), pp. 561-567

Buckley, P.J., Chapman, M., 1997. The Perception and Measurement of Transaction Costs. Cambridge Journal of Economics, Volume 21(2), pp. 127-145

Budisiswanto, N., Miharja, M., Kombaitan, B., Pradono, 2020. Institutional Coordination of the Multimodal Logistic Transportation Systems at Tanjung Priok Port, Indonesia. International Journal on Advanced Science Engineering Information Technology, Volume $10(6)$, pp. 2441-2450

Buitelaar, E., 2007. The Cost of Land Use Decisions: Applying Transaction Cost Economics to Planning \& Development. Oxford-UK: Blackwell Publishing - RICS Research

Canitez, F., 2019. Urban Public Transport Systems from New Institutional Economics Perspective: A Literature Review. Transport Reviews, Volume 39(4), pp. 511-530

Canonico, P., De Nito, E., Mangia, G., Mercurio, L., Iacono, M.P., 2013. Regulation Issues in the Italian Local Transport System: Aligning Transactions and Governance Structures. Journal of Management \& Governance, Volume 17(4), pp. 939-961 
Feiock, R.C., 2005. Institutional Collective Action and Local Governance. Paper presented at The Innovative Governance Salon, University of Southern California, pp. 1-24

Firman, T., 2009. Decentralization Reform and Local-Government Proliferation in Indonesia: Towards A Fragmentation of Regional Development. Review of Urban \& Regional Development Studies, Volume 21(2-3), pp. 143-157

Hawkins, C.V., Hu, Q., Feiock, R.C., 2016. Self-Organizing Governance of Local Economic Development: Informal Policy Networks and Regional Institutions. Journal of Urban Affairs, Volume 38(5), pp. 643-660

Hijdra, A., Woltjer, J., Arts, J., 2014. Value Creation in Capital Waterway Projects: Application of a Transaction Cost and Transaction Benefit Framework for the Miami River and the New Orleans Inner Harbour Navigation Canal. Land Use Policy, Volume 38, pp. 91-103

Hirschhorn, F., Veeneman W., van de Velde, D., 2019. Organisation and Performance of Public Transport: A Systematic Cross-case Comparison of Metropolitan Areas in Europe, Australia, and Canada. Transportation Research Part A: Policy and Practice, Volume 124, pp. 419-432

Kent, R., 1998. Marketing Research: Measurement, Methods, and Application. London: International Thomson Business Press

Kozonogova, E., Dubrovskaya, J., Dubolazova, Y., 2020. Assessment of the Contribution of Inter-Territorial Interaction in the Development of the National Economy. International Journal of Technology, Volume 11(6), pp. 1161-1170

Lowery, D., 2000. A Transaction Costs Model of Metropolitan Governance: Allocation vs. Redistribution in Urban America. Journal of Public Administration Research and Theory, Volume 10(1), pp. 49-78

Miharja, M., Woltjer, J., 2010. Inter-local Government Collaboration and Perceived Transaction Costs in Indonesian Metropolitan Transport Planning. International Development Planning Review, Volume 32(2), pp. 167-189

Mizutani, F., Smith, A., Nash, C., Uranishi, S., 2015. Comparing the Costs of Vertical Separation, Integration, and Intermediate Organisational Structures in European and East Asian Railways. Journal of Transport Economics and Policy (JTEP), Volume 49(3), pp. 496-515

Naruetharadhol, P., Srisathan, W.A., Suganya, M., Jantasombut, J., Prommeta, S., Ketkaew, C., 2020. Organizational Commitment and Engagement Practices from Applying Green Innovation to Organizational Structure: A Case of Thailand Heavy Industry. International Journal of Technology, Volume 12(1), pp. 22-32

North, D.C., 1990. Institutions, Institutional Change and Performance. Cambridge USA: Cambridge University Press

Seymour, R., Turner, S., 2002. Otonomi Daerah: Indonesia's Decentralisation Experiment. New Zealand Journal of Asian Studies, Volume 4(2), pp. 33-51

Strauss, A., Corbin, J., 1998. Basics of Qualitative Research: Techniques and Procedures for Developing Grounded Theory, (2nd ed.). Thousand Oaks. CA: Sage Publication

Thompson, G.F., 2003. Between Market \& Hierarchies: The Logic and Limits of Network Forms of Organization. New York: Oxford University Press

Ulin, P.R., Robinson, E.T., Tolley, E.E., McNeill, E.T., 2002. Qualitative Methods. A Guide for Applied Research in Sexual and Reproductive Health. North Carolina: Family Health International, USA. (Chapter 6 \& 8)

Wegelin, P., von Arx, W., 2016. The Impact of Alternative Governance Forms of Regional Public Rail Transport on Transaction Costs. Case Evidence from Germany and Switzerland. Research in Transportation Economics, Volume 59, pp. 133-142 
Weiss, R.S., 1994. Learning from Stranger: The Art and Method of Qualitative Interviewing. New York: Free Press

Williamson, O.E., 1981. The Economics of Organization: The Transaction Cost Approach. American Journal of Sociology, Volume 87(3), pp. 548-577

Williamson, O.E., 1985. The Economic Institutions of Capitalism: Firms, Markets, Relational Contracting. New York: Free Press

Zhogova, E., Zaborovskaia, O., Nadezhina, O.S., 2020. An Analysis of the Indicators of Regional Economy Spatial Development in the Leningrad Region of Russia. International Journal of Technology, Volume 11(8), pp. 1509-1518 